\title{
Using an OCD formulation in the treatment of anorexia nervosa: a useful way to understand the illness?
}

Article

Accepted Version

Jenkins, P. E. (2013) Using an OCD formulation in the treatment of anorexia nervosa: a useful way to understand the illness? The Cognitive Behaviour Therapist, 6. e8. ISSN 1754470X doi: https://doi.org/10.1017/S1754470X13000147 Available at https://centaur.reading.ac.uk/76101/

It is advisable to refer to the publisher's version if you intend to cite from the work. See Guidance on citing.

To link to this article DOI: http://dx.doi.org/10.1017/S1754470X13000147

Publisher: Cambridge University Press

All outputs in CentAUR are protected by Intellectual Property Rights law, including copyright law. Copyright and IPR is retained by the creators or other copyright holders. Terms and conditions for use of this material are defined in the End User Agreement.

www.reading.ac.uk/centaur 
Central Archive at the University of Reading

Reading's research outputs online 
7

8

9

10 Correspondence: Dr. Paul Jenkins, Cotswold House Eating Disorders Service,

11 Warneford Hospital, Warneford Lane, Headington, Oxford. OX3 7JX. Tel. +44(0)1865

12 738847, Fax: +44(0)1865 738848, E-mail: pej106@gmail.com 


\section{Abstract}

2 Background: Anorexia nervosa (AN) and obsessive-compulsive disorder (OCD) have

3 been shown to have a number of commonalities, such as genetics, neurobiology, and

4 symptoms. Approaches to treatment of AN have recently been described that take such

5 findings into account, extending interventions recommended for obsessive-compulsive

6 and anxiety disorders to AN. Aims: The current paper aims to outline a formulation

7 model of $\mathrm{AN}$ in adults, derived from literature on $\mathrm{OCD}$, and introduce this topic as a

8 fruitful area to build on existing treatment techniques, and to prompt further discussion

9 of such techniques. Methods: A formulation model is described, followed by a

10 discussion of how this might be applied to AN, using examples from clinical practice.

11 Potential benefits and difficulties are discussed. Conclusions: A formulation model is

12 suggested that can easily be adapted to $\mathrm{AN}$, complimenting existing models in eating

13 disorders.

14

15 Keywords: formulation, anorexia nervosa, obsessive-compulsive disorder, therapy

16 


\section{Introduction}

2 Anorexia nervosa (AN) has proven to be an illness with a high mortality rate, often with

3 a chronic outcome (Steinhausen, 2002). Full understanding of this illness for an

4 individual patient, usually reached by a process of psychological formulation (e.g., see

5 Bieling \& Kuyken, 2003; Lavender \& Schmidt, 2006; Persons \& Tompkins, 2007), is

6 important to design and implement a successful treatment (Persons, 2006). This

7 formulation should be unique to the individual, although generic models of pathology

8 (e.g., Fairburn, 2008; Waller et al., 2007; see also Persons, 2006) can help therapists

9 and patients come to a shared understanding of their difficulties, and how they are

10 perpetuated.

11 Features of obsessive-compulsive disorder (OCD) and obsessive-compulsive 12 personality are associated with poorer outcome and greater symptomatology in AN and 13 other eating disorders (Steinhausen, 2002; Zubieta et al., 1995), represent frequent 14 comorbid illnesses with EDs (Swinbourne \& Touyz, 2007), and there has also been 15 some genetic and biochemical evidence of an association (e.g., Enoch et al., 1998). As 16 a result of such findings, a number of authors have looked at whether AN is actually a 17 variant of an OC disorder, with some genetic, neurological, and developmental evidence 18 supporting this (e.g., Milos et al., 2002; Serpell et al., 2002; Steinglass et al., 2012). 19 Some authors (e.g., Steinglass et al., 2011; Strober et al., 2007; Waller, 2008) have 20 gone even further, suggesting that eating disorders, including AN, might be included in 21 a wider categorisation of anxiety disorders. The stance of the current article is that AN and OCD are not variants of the same condition, but that some formulation and

23 treatment techniques used in anxiety disorders may be useful when working with 24 individuals with AN. The article will explore whether a formulation model frequently 
1 used in OCD might be applicable to $\mathrm{AN}$, describing a rationale as to why this is

2 suggested and providing a template for its use. The model is targeted at the assessment

3 and formulation of AN in adults, partly as systemic treatment (rather than a CBT model)

4 is advocated in younger patients, and also that the literature referred to in this article

5 primarily concerns adult subjects; less has been written about the overlap of OCD and

6 AN in children, although Hildebrandt, Bacow, Markella, and Loeb (2012) discuss

7 similarities between methods of action in family-based therapy for adolescents and

8 CBT, specifically exposure.

A small body of evidence suggests that treatments used in anxiety disorders might

10 be useful in EDs (e.g., Steinglass et al., 2012), although some techniques reported in ED

11 treatments (e.g., Waller et al., 2007) may achieve change through similar principles.

12 Some authors have written about the process of formulation in EDs, proposing models

13 to understand the illness (e.g., Fairburn, 2008; Lavender \& Schmidt, 2006; Waller et al.,

14 2007). Given that AN is a particularly difficult illness to treat, and sufferers often show

15 denial regarding their symptoms (Vitousek, Watson, \& Wilson, 1998), a formulation

16 model that references a different condition (i.e., one that might not be seen as so

17 egosyntonic) may offer a 'back door entry' to understanding the individual and his or

18 her illness. In light of the literature discussed above, the aims of this article are to

19 suggest how use of an OCD formulation (coming from a CBT approach) can contribute

20 to an understanding of AN. Similarly, the focus on formulation throughout this article

21 is designed to help therapists, particularly those who may be less experienced in the

22 assessment and treatment of eating disorders, by outlining a more familiar model of

23 formulation that might be useful in AN. Although some anecdotal data are presented,

24 there is no formal evaluation of the utility of the model. In concert with the aims and 
1 readership of the journal, elements of the model will be individually expanded on,

2 although this level of detail may not be necessary with every patient.

\section{Empirical Rationale for use of an OCD Model in AN}

5 As detailed above, there is significant literature suggestive of some degree of 6 phenomenological, diagnostic (i.e., comorbidity), and clinical overlap between AN and

7 OC disorders, namely OCD, and a formative body of evidence supporting anxiety-based

8 treatments in AN. There is some emerging evidence supporting the benefit of CBT for

9 AN in adults (e.g., Fairburn et al., 2013), a psychological therapy with documented

10 effectiveness for the treatment of $\mathrm{OCD}$, and there exists good reason to draw parallels

11 between the two disorders.

12 Steinglass and Walsh (2006) reviewed a number of cognitive, behavioural, and

13 neurobiological commonalities of $\mathrm{AN}$ and $\mathrm{OCD}$, drawing parallels between intrusive

14 thoughts, ritualised behaviours, and cognitive inflexibility, for example. The authors

15 note similarities in the neurobiology behind AN and OCD, and build on this in a later

16 article (Steinglass et al., 2011). Steinglass and colleagues (2011) describe a treatment

17 approach, based on the original neurobiological model of Steinglass and Walsh, focused

18 on anxiety. Their model has a strong focus on behavioural fear acquisition, although

19 combines some elements of eating disordered cognitions with avoidance-based

20 behaviours. Citing the high relapse rate of current treatments, Steinglass et al. advocate

21 a shift towards the use of behavioural techniques in the treatment of AN to address

22 "both anxiety driven behaviours and irrational beliefs" (p. 140), particularly

23 emphasising exposure and response prevention. They argue that anxiety and

24 obsessional tendencies bring about certain eating behaviours (e.g., food avoidance) that 
1 lead to weight loss. This then increases anxiety and obsessionality, thus perpetuating

2 the cycle (Steinglass et al., 2010), and therefore advocate behavioural interventions that

3 promote experiential learning. However, this model does not include early experiences

4 and underlying beliefs, which are similar in anxiety and eating disorders (e.g., Pallister

5 \& Waller, 2008; Waller et al., 2000), although it could be argued that the model is

6 easily adapted in this respect.

7 The current article argues that a more complete model of AN would include these,

8 but also the phenomenon in OCD often labelled "catastrophic misinterpretations."

9 Individuals with AN often report intrusive thoughts which, similar to OCD and other

10 anxiety disorders (such as panic disorder), are misinterpreted. Cognitive behavioural

11 treatment might then look at addressing beliefs and thinking styles related to those

12 intrusions and trying to normalise behavioural responses (see below). Intrusive

13 thoughts are common in the general population, but become obsessional when they are

14 more frequent or intense, or produce greater discomfort (e.g., Rachman \& de Silva,

15 1978). Similar to the sense of 'increased responsibility' and catastrophic

16 misinterpretations in anxiety (e.g., Salkovskis, 1991; 2007), an individual with AN

17 might escalate an intrusive thought into an obsession. An example of a distortion that

18 may be seen in EDs is provided by Cooper, Todd, and Wells (2009, p. 127); 'if I get fat,

19 no-one will ever speak to me again'. It may be the case that many individuals

20 demonstrate an aversion to fatness or obesity, or a desire to weigh less (e.g., Whitaker et

21 al., 1989), but that this may be misinterpreted in those with ED pathology as having

22 more ruinous consequences, such as extreme social isolation; a trigger might be the

23 initial intrusion, which is subsequently catastrophised. 
Given this, it is argued that individuals with AN experience intrusive thoughts that are common to the general population, but interpret these thoughts as posing significant harm to themselves, and / or that they hold greater personal responsibility. This inflated responsibility then leads to a pattern of behaviours that have the unintended effect of increasing distress and also increasing the frequency and salience of intrusions (e.g., Salkovskis, 2007). Elements of this model are expanded below but, by way of example, an intrusion in AN (e.g., about eating a certain food and subsequently gaining weight) might trigger responsibility beliefs, which then result in overt efforts to reduce or escape responsibility (e.g., by exercising, or checking for perceived weight gain).

Although some similarity with existing formulations of EDs (e.g., Waller et al., 2007) exists, an OCD model (e.g., Salkovskis, 2007) includes a number of key elements, such as intrusions, responsibility appraisals, catastrophic misinterpretations, and neutralising actions (e.g., thought suppression), that may be applicable to some patients with eating disorders. Indeed, a number of studies (e.g., Coelho et al., 2012; May et al., 2010; Soetens et al., 2006) have reported evidence of such phenomena in eating pathology. The use of an OCD model with certain individuals is proposed to represent a useful account of how different thoughts and behaviours interact and it is argued that specific elements of an OCD formulation (e.g., catastrophic misinterpretations, beliefs about intrusions) may be important in understanding an individual's presenting symptoms. The model also provides a template for constructing a psychological formulation of AN. The current article does not suggest an overhaul in the way AN is conceptualised, but rather that, for some patients, a model based on OCD might offer a 'different way in' to their illness. An OCD model in particular is favoured over other anxiety formulations (e.g., panic disorder, health anxiety disorder) due to a 
1 larger evidence base suggestive of similarities between $\mathrm{AN}$ and $\mathrm{OCD}$, as well as the

2 additional flexibility and scope of an OCD model. While some elements (e.g., cognitive

3 bias, safety behaviours) are common to many formulation models of anxiety disorders

4 (and, sometimes, EDs), the OCD model presented here (Salkovskis, 2007) incorporates

5 a wide range of different phenomena (see below), and is argued to present a more

6 complete account of behaviours, cognitions, and so on that might be seen in AN. It is

7 hoped that a useful formulation model is proposed that is accessible to both patients and

8 clinicians who may not have a wealth of experience in EDs.

A CBT model of OCD, carefully applied, can help identify the above elements in

10 treatment, and suggest ways of addressing maintaining mechanisms in AN. One clear

11 advantage of using a purely OCD-type model in joint formulation with a patient with

12 AN, in the author's opinion, is that it can be used as a Socratic, hypothesis-driven way

13 of accessing the impact of thoughts and behaviours. Those with AN often have an

14 egosyntonic view of their behaviours (e.g., Holden, 1990) and it can often be difficult to

15 objectively appraise their function. However, drawing parallels with OCD behaviours

16 (which can often be easily understood by patients) represents a less challenging way of

17 introducing how ED behaviours may function to modulate anxiety, rather than to

18 maintain weight, for example; illustrations from the patient's own experience can also

19 be incorporated.

\section{Clinical Practice}

22 A description of how an OCD model (see Figure 1; Salkovskis, 2007) is used in the

23 formulation of anorexia nervosa now follows, and it is argued to provide a useful and

24 underutilised tool in eating disorders treatment. Although this is not a case series, some 
1 anecdotal data from patients is provided in order to support some of the assertions

2 made.

3
Insert Figure 1

First, as in many styles of psychotherapy formulation (e.g., Wildes \& Marcus, 2011), the patient is introduced to the model. It is suggested that this is done with reference to a fictional, archetypical example of OCD, such as an individual with compulsive hand-washing resulting from intrusive thoughts around contamination. The model is then talked through, helping the patient generate examples of each of the parts in Figure 1. Any questions or confusions are necessarily addressed, and the patient is collaboratively assisted to generalise this formulation to their own illness experiences (e.g., Overholser, 2011; Persons \& Tompkins, 2007). A useful, Socratically-driven, question might be something like "Why do you think we have been discussing OCD; what relevance might it have to your eating, for example?". Often, it is then useful to jointly go through the model, and introduce concepts of an eating disorder specifically relevant to the patient (an example is given in Figure 2). Time can be spent on the individual elements of the model (which are elaborated upon in the current article for the educational purposes), but the main aim is to understand how anxiety processes might function in eating disorders. This process of introducing and discussing the formulation may only require one session of $\mathrm{CBT}$, depending on the level of understanding and comprehension of the patient.

\section{Insert Figure 2}




\section{Early Experiences / Critical Incidents}

4 Psychological models of anxiety disorders often refer to critical incidents as activating

5 disease-specific beliefs in vulnerable individuals, and how early experiences also

6 contribute to the formation of specific assumptions and beliefs. This is a fairly

7 ubiquitous viewpoint in CBT, and is extended in the current model to AN. By

8 understanding an individual's history, a greater sense of their belief system can be

9 agreed with the therapist, and the patient helped to understand how their experiences

10 may have contributed to, say, an over-evaluation of weight and shape. Personality

11 factors (e.g., see Serpell et al., 2002; Shafran, 2002), which may also be similar across

$12 \mathrm{AN}$ and $\mathrm{OCD}$, are also relevant here. Critical incidents may include the onset of

13 dieting, loss or bereavement, and developmental influences (e.g., puberty) have also

14 been proposed as possible factors (e.g., Stewart, 2005).

16 Assumptions / General Beliefs

17 Eating disorders and OCD have been suggested to have a number of beliefs in common, 18 such as perfectionism, importance of thoughts, and control of thoughts (e.g., Lavender 19 et al., 2006; Roncero, Perpiñá, \& García-Soriano, 2011). Such beliefs might form a key 20 maintenance mechanism, common to EDs (Roncero et al., 2011), and more specific 21 beliefs might relate to other factors, such as exercise (e.g., Naylor, Mountford, \& 22 Brown, 2011). More general beliefs (e.g., schemas) are also shared between anxiety 23 disorders and eating disorders (e.g., Pallister \& Waller, 2008), which can be explored 24 using the Salkovskis (2007) model elaborated upon here. Negative self-beliefs in EDs 
1 have been discussed previously (e.g., Cooper et al., 2009), with reference to eating-

2 specific beliefs and more general self-beliefs. Such beliefs might be open to

3 misinterpretations (see below) and attentional bias (Jansen, Nederkoorn, \& Mulkens,

4 2005; see Aspen, Darcy, \& Lock, 2013, for a review of attentional bias in EDs).

5 Individuals with OCD have been shown to have a number of cognitive biases which

6 increase their level of intrusions, and therefore compulsions (e.g., Spranca, Minsk, \&

7 Baron, 1991), part of the large literature regarding attentional bias in anxiety disorders.

8 This is less well understood in EDs (Aspen et al., 2013), and it may be that bias is a

9 relatively automatic (unconscious) process or more deliberate, and, of particular note in

10 AN, may also be affected by nutritional status (e.g., Placanica, Faunce, \& Soames Job,

112002 ; see below). It may be constructive to look at such biases in anorexia nervosa on

12 an individual level, but this is also one area that is not overtly covered in the model of

13 Steinglass et al. (2011).

15 Intrusions

16 It has been suggested (e.g., Shafran, 2002; Soetens \& Braet, 2006) that individuals with

17 EDs, and particularly those who restrict their dietary intake, are likely to experience

18 unwanted (intrusive) thoughts around food, most often 'bad' foods (e.g., high calorie,

19 high fat foods). Dieters can become preoccupied with thoughts of food and eating, and

20 may be more likely to use thought suppression than non-dieters (Soetens et al., 2006).

21 Intrusive thoughts are commonly experienced in the general population (e.g., Rachman

$22 \&$ de Silva, 1978) and may be an antecedent of eating pathology, as has been suggested

23 in OCD (Salkovskis \& Campbell, 1994). However, it is the appraisal of these thoughts

24 (e.g., as personally significant) that often drives pathology, associated distress, and thus 
1 attempts at control; this may be likened to the over-evaluation of weight and shape that

2 is central to EDs (Shafran \& Robinson, 2004). As in OCD, individuals with AN may

3 have intrusions of a similar nature, and react in ways that serve to maintain and

4 encourage the disorder. For example, Salkovskis and Wahl (2004) discuss how

5 thoughts only become intrusive "depending on the person's prior experience and the

6 context in which the intrusions occur," noting also that "the majority of nonclinical

7 subjects do not regard the occurrence of intrusive thoughts as being of special

8 significance" (p. 141). Similarities might be drawn to eating disorders, with food being

9 of central importance in many people's lives; however, in nonclinical samples, there is

10 likely to be less emotion and personal responsibility attached to this (e.g., see Rawal,

11 Park, \& Williams, 2010).

\section{Misinterpretations}

14 Individuals with EDs have been found to misinterpret the consequences of thoughts

15 particularly in the domains of food, weight, and shape, but also show misinterpretations

16 related to wider beliefs, such as perfectionism or other beliefs about the self (e.g.,

17 Shafran, 2002; Vitousek \& Ewald, 1993; Williamson, Muller, Reas, \& Thaw, 1999).

18 Such misinterpretations of intrusive thoughts are likely to increase the significance and

19 persistence of these thoughts (Shafran, 2002; Shafran \& Robinson, 2004) and can also

20 lead to mood changes and safety behaviours (see below). A related concept is that of

21 thought-shape fusion (TSF; Shafran et al., 1999), a cognitive distortion akin to thought-

22 action fusion seen in OCD. Briefly, TSF occurs when thinking about a negative

23 cognition (e.g., eating a high-calorie food) leads to a change in the 'real world' (e.g., in

24 behaviour or feelings). TSF may also be strengthened through associative learning 
1 (e.g., thinking about eating a fattening food, and then eating it) and is thought to be a

2 cognitive bias that increases the likelihood of catastrophic misinterpretations and

3 maladaptive coping strategies (Shafran et al., 1999). Such processes might also be

4 accentuated by the relationship with mood changes and beliefs, for example guilt for

5 eating a certain food being (mis)interpreted as 'evidence' of personal responsibility and

6 potential negative outcomes, which may also relate to other cognitive biases, such as

7 emotional reasoning. As in OCD, belief in TSF is likely to motivate certain behaviours,

8 which in the case of AN may include dietary restriction, or body checking. Although

9 TSF is also a relatively new area of research in EDs, a few studies have documented an

10 association with ED symptoms and have suggested that it is unique to eating pathology

11 (Coelho et al., 2012). The relationship between such cognitive distortions and 12 misinterpretations in AN may benefit from further research, as has been carried out with

13 OCD (e.g., Abramowitz et al., 2001).

\section{Safety Behaviours and Neutralising Actions}

16 Although included in the lower portion of the model, safety behaviours (e.g., see

17 Pallister \& Waller, 2008) can be a particularly useful place to start, explaining the

18 rationale that safety behaviours can actually increase levels of anxiety (e.g., Deacon \&

19 Maack, 2008). This might have impacts on recovery as one aim of treatment is to

20 reduce safety behaviours, due to their role as maintaining factors in the illness (Pallister

$21 \&$ Waller, 2008). Davis and Kaptein (2006) discuss exercise as one example of a safety

22 behaviour, drawing links to obsessional personality and ritualistic behaviours in AN.

23 Similarly, attempts at thought suppression, designed to eliminate intrusive thoughts, can

24 arise from misinterpretations and increase the persistence of those intrusions. Some 
1 evidence for this in eating pathology has been found and, indeed, thought suppression

2 has been suggested (as in anxiety disorders) to increase the number of subsequent food-

3 related thoughts (e.g., May et al., 2010; Soetens et al., 2006). Other examples of safety

4 behaviours include avoidance of certain foods (e.g., those deemed to contain relatively

5 high levels of fat) and other (possibly related) dietary rules, and mirror or body

6 checking (see Fig. 2). Although there is some similarity between neutralising actions

7 and safety behaviours (Veale, 2007), it may be helpful to elaborate on this with the

8 patient, using Socratic exploration to identify the specific function of relevant thoughts

9 and / or behaviours. A number of different neutralising behaviours seen in an

10 experimental paradigm are described in Radomsky, de Silva, Todd, Treasure, and

11 Murphy (2002) (see also Kostopoulou, Varsou, \& Stalikas, 2011). Thus, in the model

12 proposed, there is some evidence for the interactive processes between neutralising

13 actions, intrusions, and misinterpretations. In the therapy session, it would be important

14 to discuss these processes with patients; treatment may involve 'breaking the cycle' of

15 problem and attempted solution (Soetens et al., 2006).

17 Mood

18 There are a number of suggested links between negative affect and EDs although, in a

19 meta-analytic review, Stice (2002) suggests that the association might be stronger in

20 bulimic disorders. The role of negative mood in eating pathology also needs to be

21 considered on an individual level, particularly as depression and low self-esteem may be antecedents to ED pathology, but also consequences (Waller et al., 2007).

23 The influence of mood on both cognitive bias and thought suppression has been

24 highlighted, for example, in that low mood may lead to more negative interpretation of 
1 thoughts (Shafran \& Robinson, 2004) or influence information processing and

2 interpretation in EDs (Aspen et al., 2013). Furthermore, Altman and Shankman (2009)

3 discuss how compensatory behaviours (e.g., purging in EDs, or handwashing in OCD)

4 function to reduce negative affect, as well as anxiety, and thus may establish a mood-

5 improving cycle. Existing models of EDs (e.g., Fairburn, 2008; Waller et al., 2007)

6 also comment that negative affect may be alleviated (albeit temporarily) by ED

7 behaviours, but that low mood might also be responsible for changes in ED behaviour.

8 Thus, low mood (as seen in the Figures) may form a complex part of an individual's

9 formulation which both drives, and is driven by, symptoms of an eating disorder.

\section{Initial Impressions}

12 Based on the author's experience of using such a model in psychological treatment

13 (which is not in $100 \%$ of cases seen in clinical practice), individuals with AN report

14 positive engagement with the model, and have generally felt it to be helpful and

15 informative. Patients appear to understand the links between intrusions, catastrophic

16 misinterpretation, and safety behaviours, and are able to assimilate these elements into

17 an overall formulation. The key to this technique is therefore drawing parallels to their

18 eating disorder. One patient, for example, remarked even before concluding the model:

19 “So, is my laxative use like a safety behaviour, then?". Another patient (see Figure 2)

20 felt that the model was very clear, practical, and easy to follow. She particularly

21 highlighted the processes (i.e., "the arrows") in the model as useful in understanding her

22 illness, and felt more informed by understanding the relationships between different

23 symptoms. She mentioned catastrophic misinterpretations (giving the example thought

24 of "if I have a bit of cake, I will put on a lot of weight"), and how she would typically 
1 cope with this through compulsive exercise. She reflected that exploring this

2 relationship in therapy helped her draw links between the thoughts and behaviours, and

3 also linked this with emotions (e.g., "If you feel stressed, it gets worse"). The

4 frequency of her compulsive exercise behaviour since decreased in treatment. Further

5 study of patient views on the use of such a model would add confidence to the

6 suggestions provided here.

7 With some individuals, it may be beneficial to focus on certain elements of the

8 model. For example, one patient was particularly interested in how she placed

9 significant emphasis on calorie-counting, and how perception of 'minor' differences in

10 the calorie content of food was (catastrophically) interpreted as having a definite impact

11 on weight. Steinglass et al. (2011) cite many pertinent examples of these elements,

12 such as fear (of food, 'fatness', weight, and so on) as akin to feared stimuli in anxiety

13 disorders. As in OCD, such thoughts are then acted on through ritualised and rigid

14 behaviours (see Pallister \& Waller, 2008; Steinglass \& Walsh, 2006), which serves to

15 maintain (or increase) both the thoughts and associated anxiety. Neutralising and safety

16 behaviours may thus increase other elements of pathology (see Figures), such as

17 increasing intrusions via thought suppression or by maintaining illness-related beliefs

18 through avoidance of perceive harm or exposure, preventing disconfirmation of these

19 beliefs. As Waller (2008) notes: "as with all such safety behaviours, the immediate

20 effect is anxiety reduction, but the longer-term effect is maintenance and elaboration of

21 the anxiety" (p. 169). Pallister and Waller (2008) provide useful examples of seeing

22 safety behaviours in eating disorders, whilst also pointing out some of the difficulties in

23 decreasing the use of these in patients. Although such illustrations can likely be

24 described to patients without reference to the complete formulation model outlined here, 
1 it is argued that the model provides a thorough understanding of how safety behaviours

2 function, and what beliefs might underlie them. Thus, it is hoped that such a

3 formulation can help patients to see the impact of their safety behaviours, and appreciate

4 some of the cognitive factors that might maintain their pathology. Further study will be

5 required to identify techniques based on these suggestions (e.g., Steinglass et al., 2012)

6 and to look at the therapeutic effectiveness of such techniques. Furthermore, as in

7 anxiety disorders (e.g., Sloan \& Telch, 2002), safety behaviours might maintain fear,

8 and also negatively affect treatment outcome. Continued exposure to anxiety-provoking

9 triggers can provide an individual also with "evidence about the link between anxious

10 stimuli and catastrophic outcomes," and developing new memories and associations

11 (Hildebrandt et al., 2012, p. e9).

12 It is not yet known for which patients (if not all of those with AN) this model may

13 - or may not - be useful, and future work may help to elucidate this. Initial suggestions

14 from the current author are that those with a chronic presentation, or those who report

15 high egosyntonicity and / or limited insight into their illness may benefit from this

16 approach, which argues that a non-confrontational, Socratic approach is more likely to

17 foster a positive therapeutic relationship and open the possibility for subsequent

18 behavioural change. However, as noted above, AN is frequently an egosyntonic illness,

19 and the model may be helpful for many patients regardless of level of insight. It may

20 also be helpful in individuals who have both AN and OCD that are functionally linked,

21 as some ED treatment manuals suggest simultaneous treatment in such cases (see

22 Waller et al., 2007, p. 250). A comprehensive formulation approach may help sufferers

23 appreciate the impacts of their behaviours, and Waller et al. (2007) describe how good

24 formulation is essentially a set of hypotheses that helps both patient and clinician gain 
1 insight into the illness. It can help select appropriate interventions, but it may also be

2 necessary to include elements of more complex formulation models, and the model

3 presented here may be useful as a starting point to understanding the illness, or as an

4 addition to an existing model. It should also be emphasised that what is argued here is

5 an approach to understanding AN using a formulation that has elements of existing

6 models (e.g., Waller et al., 2007) but one that elaborates on key factors that are likely to

7 maintain AN. AN and OCD are different psychiatric disorders, and, despite significant

8 similarities, there are different traits that distinguish the two illnesses (e.g., Steinglass \&

9 Walsh, 2006; Sunday, Halmi, \& Einhorn, 1995) and considering the two as distinct

10 entities has a number of clinical advantages (Holden, 1990).

\section{A Note on Low Weight and Dietary Restriction}

13 The model here has been aimed at adults with AN, a disorder for which low body 14 weight is of central importance. The exact contribution of weight loss needs to be 15 understood, therefore, particularly as it has been suggested that anxiety predates weight 16 loss in many cases, and often persists after restoration of normal weight (Strober et al., 17 2007). It may be the case that starvation and / or weight loss are responsible for all, or many, of the OCD-type symptoms seen in AN, i.e., that obsessions and compulsions (particularly around food) can arise from malnourishment and food restriction (see

20 Serpell et al., 2002).

As Davis and Kaptein (2006) note, "It is quite probable that some of the psychological and behavioural symptoms of AN are either caused - or at least exacerbated - by malnutrition" (p. 210; also Steinglass \& Walsh, 2006). However,

24 there is also some evidence that OC beliefs in EDs are present regardless of the level of 
1 emaciation (Roncero et al., 2011) although further study is needed in this area. In the

2 context of the formulation model suggested here, the influence of low weight and

3 dietary restriction may be evident in different parts of the model, which will need to be

4 explored on an individual level. For example, dietary restriction may operate as a safety

5 behaviour (to prevent the feared outcome, e.g., uncontrolled weight gain) or as a

6 precipitating event. It might also increase attentional bias (Placanica et al., 2002), have

7 a reciprocal relationship with food-related anxiety (Steinglass et al., 2011) and, as

8 Waller et al. (2007) remark, might bring about low mood. The effects of starvation

9 have also been suggested to intensify the trait of cognitive inflexibility (Friederich \&

10 Herzog, 2011; Tchanturia \& Hambrook, 2010), and thus normalising eating patterns and

11 restoring weight should form part of treatment goals for such individuals.

12 Although it as yet appears that weight restoration is only a part of long-term

13 recovery, the importance of addressing low weight and dietary restriction is central in

14 AN, and should be considered in a psychological formulation of an individual sufferer;

15 this may be prioritised for treatment in light of the seriousness or risk of such

16 behaviours. Treatment framed around the formulation will then, therefore, consider

17 how best to address symptoms such as weight loss and restriction, and it may be that the

18 interventions vary according to the hypothesised role of these symptoms and behaviours

19 within a given individual.

\section{$21 \quad$ Limitations}

22 The current paper aims to introduce a model of formulation and offers no systematic

23 assessment of its efficacy or acceptability. Furthermore, numerous reviews of the

24 'overlap' between OCD and AN have been expertly written (e.g., Altman \& Shankman, 
1 2009; Pallister \& Waller, 2008; Serpell et al., 2002; Steinglass et al., 2011), and the

2 current paper does not offer a comprehensive overview of such issues. Thus, empirical

3 studies may be needed in order to more fully examine how useful the proposed model is

4 in clinical settings. The various similarities noted above between AN and OCD suggest

5 that an OCD-specific formulation might be the most helpful, as it includes a number of

6 elements thought to be similar across the two disorders. However, alternative models of

7 anxiety may be just as helpful in understanding AN, as might current models of EDs,

8 although it is also argued here that basic CBT principles (e.g., avoidance, exposure to

9 feared stimuli, links with mood) can be included in the above formulation, whilst also

10 including elements more in common with OCD; in this way, the model is seen as

11 flexible but also comprehensive.

12 In order for treatment to work well, the principles of CBT must be adhered to, and

13 the formulation presented here is no exception. Formulation of the complex cases that

14 are so often seen in $\mathrm{AN}$ requires preparation and mindful planning on the part of the

15 therapist. Some of the techniques, while seemingly benign, might provoke

16 misinterpretation on the part of the patient, and may in fact be counterproductive to the

17 aims of treatment. Novice therapists are advised to be judicious in the application of an

18 OCD formulation model to AN and addressing elements such as safety behaviours.

19 Thus, therapists practising with this model should feel confident and competent in

20 working with such individuals, and seek appropriate supervision where necessary.

\section{Conclusions}

23 The current article adds to existing opinion regarding the advantages of conceptualising 24 eating disorders as similar in many ways to anxiety disorders, such as obsessive- 
1 compulsive disorder. It builds on existing reports (e.g., Steinglass et al., 2011; 2012) by

2 providing clinical techniques to approach formulation in anorexia nervosa, a notoriously

3 difficult-to-treat illness with frequent anxiety symptoms and high relapse rates

4 (Steinglass et al., 2011; Steinhausen, 2002).

5 The formulation proposed in the current study seems acceptable to patients, and,

6 from the author's experience, seems to help both patient and therapist understand eating

7 behaviours in a number of ways that have not been fully explored or combined in

8 existing models. Case series and controlled studies will be required to test the efficacy

9 and utility of this approach.

10 Rather than being seen as alternative to existing models (e.g., Pallister \& Waller,

11 2008; Steinglass et al., 2011), the ideas advanced in the current article might be seen as

12 a compliment. It is hoped that the ideas suggested will help therapists, particularly

13 those who feel they have a limited understanding of anorexia nervosa (e.g., see Kaplan

14 \& Garfinkel, 1999; Yager, 1992). Similarly, the extent to which these ideas are used

15 might also depend on patient factors. For example, a patient's level of engagement, or

16 perhaps insight into their illness, might suggest how direct to be in formulating their ED

17 behaviours; patients who present with high levels of denial (e.g., Vitousek et al., 1998)

18 might be helped to understand their condition by drawing parallels to OCD.

20 Summary

21 There is some degree of conceptual, genetic, symptom, and phenomenological overlap 22 between anxiety disorders, such as OCD, and anorexia nervosa (AN). The article 23 describes a popular formulation model of OCD which can be used by practitioners to 24 understand some aspects of AN. This is seen as a compliment to existing formulation 
1 models in eating disorders, and it is hoped that it can be used as a tool to both guide an

2 intervention and also to help patients become more aware of some of the maintaining

3 factors in their illness. Further empirical evaluation of the model is required.

$5 \quad$ Recommended follow-up reading

6 Pallister E, Waller G (2008). Anxiety in the eating disorders: Understanding the 7 overlap. Clinical Psychology Review 28, 366-386.

8 Steinglass J, Sysko R, Glasofer D, Albano AM, Simpson HB, Walsh BT (2011). Rationale for the application of Exposure and Response Prevention to the treatment of anorexia nervosa. International Journal of Eating Disorders 44, 134-141.

13 Learning objectives

14 1. To understand the use of an OCD formulation in AN

15 2. To apply a model of anxiety disorders to an eating disorder (AN)

163 . To gain insight into some of the potential maintaining mechanisms of AN

17 4. To reflect on the similarities between two distinct psychiatric disorders

19 Declaration of interests

20 None

\section{Acknowledgements}

23 The author would like to thank two anonymous reviewers for their helpful suggestions

24 in revising the manuscript. 


\section{References}

2 Abramowitz JS, Whiteside S, Lynam D, Kalsy S (2001). Is thought-action fusion specific to obsessive-compulsive disorder?: A mediating role of negative affect. Behaviour Research and Therapy 41, 1069-1079.

Altman SE, Shankman SA (2009). What is the association between obsessivecompulsive disorder and eating disorders? Clinical Psychology Review 29, 638646.

Aspen V, Darcy AM, Lock J (2013). A review of attention biases in women with eating disorders. Cognition \& Emotion 27, 820-838.

10 Bieling PJ, Kuyken W (2003). Is cognitive case formulation science or science fiction? Clinical Psychology: Science and Practice 10, 52-69.

Coelho J, Baeyens C, Purdon C, Pitet A, Bouvard M (2012). Cognitive distortions and eating pathology: Specificity of thought-shape fusion. Behaviour Research and Therapy 50, 449-456.

Cooper M, Todd G, Wells A (2009). Treating Bulimia Nervosa and Binge Eating: An Integrated Metacognitive and Cognitive Therapy Manual, Hove, UK: Routledge.

Davis C, Kaptein S (2006). Anorexia nervosa with excessive exercise: A phenotype with close links to obsessive-compulsive disorder. Psychiatry Research 142, 209217.

Deacon B, Maack DJ (2008). The effects of safety behaviors on the fear of contamination: An experimental investigation. Behaviour Research and Therapy 46, 537-547. 
1 Enoch M-A, Kaye WH, Rotondo A, Greenberg BD, Murphy DL, Goldman D

2 (1998). 5-HT $2 \mathrm{~A}$ promoter polymorphism -1438G/A, anorexia nervosa, and obsessive-compulsive disorder. The Lancet 351, 1785-1786.

Fairburn CG (2008). Cognitive Behaviour Therapy and Eating Disorders, New York: Guilford Press.

Fairburn CG, Cooper Z, Doll HA, O'Connor ME, Palmer RL, Dalle Grave R (2013). Enhanced cognitive behaviour therapy for adults with anorexia nervosa: A UK-Italy study. Behaviour Research and Therapy 51, R2-R8. DOI: 10.1016/j.brat.2012.09.010

Friederich H-C, Herzog W (2011). Cognitive-behavioral flexibility in anorexia nervosa. Current Topics in Behavioral Neurosciences 6, 111-124.

Hildebrandt T, Bacow T, Markella M, Loeb KL (2012). Anxiety in anorexia nervosa and its management using family-based treatment. European Eating Disorders Review 20, e1-e16.

Holden NL (1990). Is anorexia nervosa an obsessive-compulsive disorder? The British Journal of Psychiatry 157, 1-5.

Jansen A, Nederkoorn C, Mulkens S (2005). Selective visual attention for ugly and beautiful body parts in eating disorders. Behaviour Research and Therapy 43, 183-196.

Kaplan AS, Garfinkel PE (1999). Difficulties in treating patients with eating disorders: A review of patient and clinician variables. The Canadian Journal of Psychiatry 44, 665-670. 
1 Kostopoulou M, Varsou E, Stalikas A (2011). Thought-shape fusion in bulimia nervosa: An experimental investigation. Eating and Weight Disorders 16, e86e92.

Lavender A, Schmidt U (2006). Cognitive-behavioural case formulation in complex eating disorders. In Case Formulation in Cognitive Behaviour Therapy: The Treatment of Challenging and Complex Cases (ed. N. Tarrier), pp. 238-262. Hove, UK: Routledge.

Lavender A, Shubert I, de Silva P, Treasure J (2006). Obsessive-compulsive beliefs and magical ideation in eating disorders. British Journal of Clinical Psychology 45, 331-342.

May J, Andrade J, Batey H, Berry L-M, Kavanagh DJ (2010). Less food for thought. Impact of attentional instructions on intrusive thoughts about snack foods. Appetite 55, 279-287.

Milos G, Spindler A, Ruggiero G, Klaghofer R, Schnyder U (2002). Comorbidity of obsessive-compulsive disorders and duration of eating disorders. International Journal of Eating Disorders 31, 284-289.

Naylor H, Mountford V, Brown G (2011). Beliefs about excessive exercise in eating disorders: The role of obsessions and compulsions. European Eating Disorders Review 19, 226-236.

Overholser JC (2011). Collaborative empiricism, guided discovery, and the Socratic method: Core processes for effective cognitive therapy. Clinical Psychology: Science and Practice 18, 62-66.

Pallister E, Waller G (2008). Anxiety in the eating disorders: Understanding the overlap. Clinical Psychology Review 28, 366-386. 
1 Persons JB (2006). Case formulation-driven psychotherapy. Clinical Psychology: Science and Practice 13, 167-170.

3 Persons JB, Tompkins MA (2007). Cognitive-behavioral case formulation. In Handbook of Psychotherapy Case Formulation, $2^{\text {nd }}$ Edition (ed. T.D. Eells), pp. 290-316. New York: Guilford Press.

6 Placanica JL, Faunce GJ, Soames Job RF (2002). The effect of fasting on attentional biases for food and body shape / weight words in high and low Eating Disorder Inventory scorers. International Journal of Eating Disorders 32, 79-90.

9 Rachman S, de Silva P (1978). Abnormal and normal obsessions. Behaviour

Radomsky AS, de Silva P, Todd G, Treasure J, Murphy T (2002). Thought-shape fusion in anorexia nervosa: An experimental investigation. Behaviour Research and Therapy 40, 1169-1177.

Rawal A, Park RJ, Williams JMG (2010). Rumination, experiential avoidance, and dysfunctional thinking in eating disorders. Behaviour Research and Therapy 48,

Roncero M, Perpiñá C, García-Soriano G (2011). Study of obsessive compulsive 851-859. DOI: 10.1016/j.brat.2010.05.009 beliefs: Relationship with eating disorders. Behavioural and Cognitive Psychotherapy 39, 457-470.

Salkovskis PM (1991). The importance of behaviour in the maintenance of anxiety and panic: A cognitive account. Behavioural Psychotherapy 19, 6-19.

Salkovskis PM (2007). Psychological treatment of obsessive-compulsive disorder. Psychiatry 6, 229-233. 
1 Salkovskis PM, Campbell P (1994). Thought suppression induces intrusion in naturally occurring negative intrusive thoughts. Behaviour Research and Therapy $32,1-8$.

Salkovskis PM, Wahl K (2004). Treating obsessional problems using cognitivebehavioral therapy. In Cognitive Therapy Across the Lifespan: Evidence and Practice (ed. M.A. Reinecke \& D.A. Clark), pp. 138-171. Cambridge, UK: Cambridge University Press.

Serpell L, Livingstone A, Neiderman M, Lask B (2002). Anorexia nervosa: Obsessive-compulsive disorder, obsessive-compulsive personality disorder, or neither? Clinical Psychology Review 22, 647-669.

Shafran R (2002). Eating disorders and obsessive compulsive disorder. In Cognitive Approaches to Obsessions and Compulsions: Theory, Assessment, and Treatment (ed. R.O. Frost \& G. Steketee), pp. 215-231. Oxford, UK: Elsevier Science.

Shafran R, Robinson P (2004). Thought-shape fusion in eating disorders. British Journal of Clinical Psychology 43, 399-407.

Shafran R, Teachman BA, Kerry S, Rachman S (1999). A cognitive distortion associated with eating disorders: Thought-shape fusion. British Journal of Clinical Psychology 38, 167-179.

Sloan T, Telch MJ (2002). The effects of safety-seeking behavior and guided threat reappraisal on fear reduction during exposure: An experimental investigation. Behaviour Research and Therapy 40, 235-251.

Soetens B, Braet C (2006). 'The weight of a thought': Food-related thought suppression in obese and normal-weight youngsters. Appetite 46, 309-317. 
1 Soetens B, Braet C, Dejonckheere P, Roets A (2006). 'When suppression backfires': The ironic effects of suppressing eating-related thoughts. Journal of Health Psychology 11, 655-668. DOI: 10.1177/1359105306066615

Spranca M, Minsk E, Baron J (1991). Omission and commission in judgement and choice. Journal of Experimental Social Psychology 27, 76-105.

Steinglass J, Walsh BT (2006). Habit learning and anorexia nervosa: A cognitive neuroscience hypothesis. International Journal of Eating Disorders 39, 267-275.

Steinglass J, Sysko R, Mayer L, Berner LA, Schebendach J, Wang Y, Chen H, Albano AM, Simpson HB, Walsh BT (2010). Pre-meal anxiety and food intake in anorexia nervosa. Appetite 55, 214-218.

Steinglass J, Sysko R, Glasofer D, Albano AM, Simpson HB, Walsh BT (2011). Rationale for the application of Exposure and Response Prevention to the treatment of anorexia nervosa. International Journal of Eating Disorders 44, 134-141.

Steinglass J, Albano AM, Simpson B, Carpenter K, Schebendach J, Attia E (2012). Fear of food as a treatment target: Exposure and response prevention for anorexia nervosa in an open series. International Journal of Eating Disorders 45, 615-621. DOI: $10.1002 /$ eat.20936

Steinhausen H-C (2002). The outcome of anorexia nervosa in the $20^{\text {th }}$ Century. The American Journal of Psychiatry 159, 1284-1293.

Stewart A (2005). Disorders of eating control. In Cognitive Behaviour Therapy for Children and Families, (ed. P. Graham), pp. 359-384. Cambridge, UK: Cambridge University Press. 
1 Stice E (2002). Risk and maintenance factors for eating pathology: A meta-analytic review. Psychological Bulletin 128, 825-848.

Strober M, Freeman R, Lampert C, Diamond J (2007). The association of anxiety disorders and obsessive compulsive personality disorder with anorexia nervosa: Evidence from a family study with discussion of nosological and neurological evidence. International Journal of Eating Disorders 40, S46-51.

Sunday SR, Halmi KA, Einhorn A (1995). The Yale-Brown-Cornell Eating Disorder Scale: A new scale to assess eating disorder symptomatology. International Journal of Eating Disorders 18, 237-245.

Swinbourne JM, Touyz SW (2007). The co-morbidity of eating disorders and anxiety disorders. European Eating Disorders Review 15, 253-274.

Tchanturia K, Hambrook D (2010). Cognitive Remediation Therapy for anorexia nervosa. In The Treatment of Eating Disorders: A Clinical Handbook, (ed. C.M. Grilo \& J.E. Mitchell), pp. 130-149. New York, NY: Guilford Press.

Veale D (2007). Psychopathology of obsessive-compulsive disorder. Psychiatry 6, 225-228.

Vitousek K, Ewald LS (1993). Self-representation in eating disorders: A cognitive perspective. In The Self in Emotional Distress: Cognitive and Psychodynamic Perspectives, (ed. Z.V. Segal \& S.J. Blatt), pp. 221-257. New York, NY: Guilford Press.

Vitousek K, Watson S, Wilson GT (1998). Enhancing motivation for change in treatment-resistant eating disorders. Clinical Psychology Review 18, 391-420.

Waller G (2008). A 'trans-transdiagnostic' model of the eating disorders: A new way to open the egg? European Eating Disorders Review 16, 165-172. 
1 Waller G, Ohanian V, Meyer C, Osman S (2000). Cognitive content among bulimic women: The role of core beliefs. International Journal of Eating Disorders 28, $235-241$.

Waller G, Cordery H, Corstorphine E, Hinrichsen H, Lawson R, Mountford V, Russell K (2007). Cognitive Behavioral Therapy for Eating Disorders: A Comprehensive Treatment Guide, New York: Cambridge University Press.

Whitaker A, Davies M, Shaffer D, Johnson J, Abrams S, Walsh BT, Kalikow K (1989). The struggle to be thin: A survey of anorexic and bulimic symptoms in a non-referred adolescent population. Psychological Medicine 19, 143-163.

Wildes JE, Marcus MD (2011). Development of emotion acceptance behaviour therapy for anorexia nervosa: A case series. International Journal of Eating Disorders 44, 421-427.

Williamson DA, Muller SL, Reas DL, Thaw JM (1999). Cognitive bias in eating disorders: Implications for theory and treatment. Behavior Modification 23, 556577.

Yager J (1992). Patients with chronic, recalcitrant eating disorders. In Special Problems in Managing Eating Disorders (ed. J. Yager, H.E. Gwirtsman, \& C.E. Edelstein), pp. 205-237. Washington, DC: APA Press.

Zubieta JK, Demitrack MA, Fenick A, Krahn, DD (1995). Obsessionality in eatingdisorder patients: Relationship to clinical presentation and two-year outcome. Journal of Psychiatric Research 4, 333-342. 
1 Figure 1: Cognitive model of OCD. As presented in Salkovskis (2007, p. 229).

2 Reproduced with permission of Elsevier B. D.

3

4 
1 Figure 2: Cognitive model of OCD, applied to anorexia nervosa

2 